\title{
Contemporary Girls Studies
}

\author{
Reflections on the Inaugural International \\ Girls Studies Association Conference
}

Victoria Cann, Sarah Godfrey, and Helen Warner

\section{$\cos 80$}

As we move towards the second International Girls Studies Association Conference, to be held at the University of Notre Dame, Indiana, in February 2019, we reflect on the work of the scholars and practitioners who presented at our first conference in April 2016, in Norwich, UK. In this special issue of Girlhood Studies: An Interdisciplinary Journal we highlight the diversity of articles presented at the conference that provided us with a sense of the breadth of research in girls studies to date.

Founded in 2011, the International Girls Studies Association (IGSA), a professional organization, seeks to bring together scholars and practitioners at all career stages and from all (inter)disciplinary fields from anywhere in the world to promote this burgeoning area of research and activism. As our website ${ }^{1}$ details, "The Association is designed to share information and other resources, facilitate discussion, and work towards the further development of the field of girls studies" (2018: n.p.). It is important to note that we are not writing here as IGSA, but, rather, as three of the many people who helped to organize, and were inspired by, the inaugural IGSA conference in 2016.

As we write this introduction the call for papers for the 2019 IGSA conference has just closed. We are also in the process of formalizing our organization as an academic association. It seems then not only timely, but also necessary to reflect on the state of the field and the context in which we are located as a network of scholars. Speaking as feminists (while acknowledging that not all scholars in this area identify as such), it is useful to remind ourselves that when we are pushing against white supremacy and neoliberal imperatives, we must continue to reflect critically on our processes and structures as well as on our outcomes. In this introduction we undertake such 
critical reflection, using the 2016 conference as a way of interrogating the contemporary field and considering its future.

\section{6: A Turning Point?}

Not only was 2016 the year that brought together over 150 scholars from around the globe to the University of East Anglia to discuss and debate issues relevant to the vibrant field of girls studies, it was also a year fraught with global political and economic unease. The year was notable for Donald Trump's successful presidential campaign, the UK taking a step to the right and voting to leave the EU, and the world's on-going refugee crisis resulting from the war in Syria, as well as many other conflicts. In these troubling socio-political contexts, it is girls who find themselves disproportionately affected by the double disadvantage of their age and sex/gender. In the UK, where the University of East Anglia at which we work is located, the dual issues of Brexit and austerity continue to have an impact on girls, and it is poor, working class, inner city girls of color who are disproportionally affected as Maya Goodfellow (2016) has pointed out. Indeed, the leading NGO for girls' rights, Plan UK, released its report, The State of Girls Rights in the UK, in September 2016. The report found that, despite the apparent accomplishments of postfeminism, girls feel unsafe online and on the street with sexual harassment being experienced by the vast majority of respondents. The report drew its findings from several locations across the UK in an attempt to provide an overall sense of the current situation. What was striking, though, was the emphasis throughout on the many ways in which girls and girls' rights in the UK are often "concealed, either under the ageless category of 'women' or the gender-neutral category of 'children"” (Plan UK 2016: 146). Indeed, many of the papers presented and the conversations held over the course of the 2016 conference seemed to anticipate these concerns. For example, questions around girls' digital citizenship and online rights were asked and girls' political activism was discussed. Furthermore, the importance of methodological and creative approaches to collaborative research in which girls are partners and creators, not simply passive participants or objects of study, was also emphasized.

As was to be expected of a conference that focused on a marginalized group (which has within it its own intersections of oppression), much of the debate was somber in tone. However, such is the emancipatory potential of girlhood studies that explicit avenues of hope for the future were explored. 
A clear attempt to bring together theory and practice was foregrounded in the plenary panel, Pedagogies of Girlhood: Schools, Feminism and Media, led by some of the leading scholars and practitioners in this area (Hanna Retallack and Jessica Ringrose, Marnina Gonick, and Ileana Jimenez). As Jimenez (perhaps better known as blogger Feminist Teacher) wrote on her blog (2016) about the conference, "This was the first time that a global girls' studies conference featured teachers and researchers sharing our work together" (n.p.). In the same blog post, Jessica Ringrose reflected that "this plenary was a wonderful way to showcase the collaborative impact activistbased research work is making" (n.p.). A key strength of any interdisciplinary conference and seminar that explores contemporary childhoods and girlhoods is not only the breadth of perspectives and approaches that are brought together but also that the innovative and important interventions of girlhood studies, that see academics working alongside practitioners, artists, NGOs and community groups, can be foregrounded. The wide-ranging discussions and impressive array of case studies that were presented during the conference demonstrated the real potential of girls studies scholars to form productive collaborations with partners outside of academia in order to produce work that has both academic merit and meaningful impact.

Other papers presented at this conference celebrated the creativity and agency of girls in a range of contexts that recalled Mary Celeste Kearney's Girls Make Media (2006). From YouTube videos and vlogging through to zine making, creative writing, and speech, we saw the many ways in which (some) girls navigate the cultural landscape, reshaping resurgent feminist gender politics in the process. These presentations provided a valuable reminder of the importance of research on girlhood that works in ways that facilitate girls' agency to ensure that we speak with, not for them. As the Plan UK (2016) report put it, it is the girls who are the experts in their own lives, so our roles, as academics, teachers, and practitioners should therefore be to create cultural and educational spaces to which and in which all girls can contribute. Some of the best ways of doing this include working with partners from outside of academia — schools, youth groups, and community groups but also NGOs and welfare organizations.

Right now, girls studies is uniquely positioned to deal with a range of pressing issues; from economics and law to sexual rights and representation, the areas and approaches that make up this broad field are many. Over the course of the conference it was clear that there is much to gain from this diversity and much to learn from those academic areas that sit adjacent to our own individual niches. The conference began with a keynote talk by 
Catherine Driscoll, without whom a conference of this magnitude and breadth might never have been possible. Her initial idea to bring together scholars working in girlhood studies to create the International Association of Girls Studies in 2010 has been instrumental in fostering a vibrant academic network that has recently been formalized as an academic association. In her keynote talk, Driscoll discussed the meaning of girl and girls studies in the present and set out an agenda for the future of academic work in the field. In Mary Celeste Kearney's closing keynote presentation that offered a reflection on her Girls Make Media (2006) over ten years, we saw clear evidence of her dedication to, and enthusiasm for, girls studies, and her absolute conviction that the lives, experiences, histories, stories, and voices of girls must be more fully included in our scholarship.

Rozena Maart offered a powerful reminder of the white supremacy that punctuates all academic interrogation into girls' lives. Maart (whose name, she reminds us, comes out of the African slave trade) asked us to consider why so much of girls studies (like its predecessors women's studies and gender studies) overlooks the role of coloniality and empire building in its development and scholarship. Maart, drawing on her literary and philosophical background to raise the claim that freedom is something that never comes to girls raised in the context of colonial enslavement, considered what it means to be such a girl. Furthermore, we need to remember that it is white scholars who have benefitted from the history of enslavement that many of them appear to resist as potentially discomfiting. As Maart pointed out in her keynote talk, "White supremacy can only be dismantled if people are willing to put themselves on the line" which is, arguably, the very least that white scholars of girlhood can do. As Akwugo Emejulu's recent writing has highlighted, "Feminists must confront the exclusionary practices in their activism" (2018: 273), thus indicating that Maart's calls for white reflexivity and power redistribution in the academy remain, to some extent, unanswered.

\section{Looking back, Moving forward}

As Jessalynn Keller (2016) writes, the word girl is a powerful one but this has not always been seen to be the case. In their introduction to Seven Going on Seventeen: Tween Studies in the Culture of Girlhood (2007) almost a decade earlier than Keller's observation, Claudia Mitchell and Jacqueline ReidWalsh made the wry observation that anything to do with girl's cultures, much less the studying of such cultures had, typically, been seen as unim- 
portant both in popular culture and in the academy, an attitude that many scholars of gender and girlhood have encountered. In clear opposition to this, the academic integrity and the conceptual and methodological scope of the initial IGSA conference demonstrated the shaky patriarchal ground on which such claims of triviality and irrelevance are founded. Girls studies has come a long way, branching across media and cultural studies, sociology, history, literature, art history, archeology, anthropology, ethnography, development studies and international relations, creative arts, and so forth. When it comes to the development of the discipline British scholar Chris Griffin wrote that "it became harder to ignore girls . . . quite so comprehensively by the 1990s" (2004: 33) and US scholar Kearney reflected that when she entered grad school in 1990 "girls studies did not exist" (2009: 1). The scholarship of girls studies has grown expansively since the work of scholars (most notably Angela McRobbie (1978a, 1978b) and Chris Griffin (1985)) at the Centre for Contemporary Cultural Studies in the 1970s and 1980s was first undertaken (see, also, McRobbie and Nava 1984). McRobbie's (1990) groundbreaking book Feminism and Popular Culture helped to establish the theoretical dexterity that characterizes much of contemporary girls studies. This work brought cultural studies, media studies, and sociological studies together to provide one of the first book-length academic considerations of girlhood and girls' cultures. While the cultural and technological landscapes may have changed substantially during this time, many of the questions, concerns, and approaches that remain at the fore of this area can be traced back to this early work. In the intervening years scholars including Driscoll (2002), Harris (2004), Mitchell and Reid-Walsh (2005), and Kearney (2006) all published books that built the conceptual and methodological frameworks of the field. As demonstrated at the 2016 IGSA conference, the methodological approaches in girls studies remain diverse, with critical and reflexive approaches being taken in qualitative and quantitative research, as well as in ethnographic interrogations and textual analyses of girls' lives in both the past and the present. Since the 2016 IGSA conference, a special issue of Girlhood Studies: An Interdisciplinary Journal (2016) on the topic of Ethical Practices in Girlhood Studies, guest edited by April Mandrona, has served to strengthen the methodological rigor of the work undertaken in this field.

Alongside this intellectual movement, the lives of girls have also shifted rapidly. Postfeminism, argued to be the defining sensibility of the early 2000s (Gill 2007), has emerged and so the ways in which scholars have come to understand girls' lives have shifted too. It has been suggested that the "dis- 
tinctly neoliberal and postfeminist" (Gill and Scharff 2011: 1) context has affected the lives of girls and their engagement with femininity in a range of ways particularly in terms of how girls negotiate their lived realities (see also McRobbie 2009). The emphasis that neoliberal and postfeminist rhetoric such as the notion of girl power places on self-making and individualism have "enabled the current generation of young women to see themselves, and to be seen, as enjoying new freedoms and opportunities" (Harris 2004: $8)$. Girls have therefore been understood as being able to embody what Harris (2004) thinks of as flexible subjectivities. However, what the papers at the 2016 IGSA conference also revealed was the extent to which such flexibilities are open to, and enjoyed by, only a relatively narrow set of girlsthose who are middle-class, white, able-bodied, heterosexual, cisgender, and who speak English as a first language.

Despite the academic reach of girls studies now, and, despite the best intentions of many academics who explicitly identify as feminist scholars, there are still notable gaps in both the work being done and in the range of people who have the academic, economic, and cultural privilege to do the work. As organizers of the conference we were delighted when submissions came in from outside the typical enclaves of North America, Western Europe, and Australia, and we were keen to include scholars, students, and colleagues from those spaces that are less visible in the Anglo-Americancentric world of contemporary humanities. We were excited to receive proposals from scholars and practitioners from China, India, South Africa, and Russia. Unfortunately, not all these scholars were able to take up our invitation to present at the conference either because of visa difficulties or because the travel and accommodation costs were financially prohibitive. It was therefore inevitable, perhaps, that the conference was dominated by white Anglophone academics, and that this undoubtedly focused the discussions and presentations on particular issues while others remained invisible, absent, and unspoken. The conference was certainly international, but it was far from globally inclusive. As an organizing committee of white, Anglophone academics most of whom came of age in a period in which second wave feminism was being (rightly) critiqued for being impervious to questions of race and ethnicity, we were struck by the fact that there is still much work to be done if girls studies is to fulfil its potential as a field of study that is both inclusive and reflexive. That is not to suggest, however, that important work in this area is not being done. For example, the "Black Girl Movement" Conference was being held at Columbia University even as IGSA 2016 was in progress. In a bid to bring together these important 
conversations, Hey Girl Global ${ }^{2}$ used hashtags from both conferences to create dialogue across events.

It was not just in terms of global representation that the conference demonstrated the pressing need for feminist academics to pursue inclusivity actively as a political and ethical practice; there was a predominance of work that focused on heteronormative frames of girlhood. A pressing issue here has to do with the limited presence or, rather, absence, of trans and queer girls and the urgent need to denaturalize the very concept of girlhood both as a lived experience and as a theoretical concept. Not only does this enable us to better see the specificities of queer and trans girls, but their inclusion in relevant literature is important in resisting the reproduction of the gender binary that many of us critique (see Monaghan 2016). Such questions and concerns also force consideration of what girls studies as a field does when it comes to gender analysis; we need to question whether its very existence reinforces the gender binary.

It is, of course, more than ten years since Marnina Gonick asked the probing question, "Are queer girls, girls?" (2006: 122), but at IGSA 2016 queer girlhoods were the focus of just one panel, and there were just two papers that explored questions of transgirlhood. Rachel Reinke presented her thoughts on the importance of transgirl subjectivities using Jazz Jennings, an American transgender teenage girl who is an LGBT rights activist, as a case study. In this paper, Reinke built a persuasive argument about the current absence of transgirls in girlhood studies. Melinda de Jesús built on this in her discussion of cis-genderism in pedagogies, scholarship, and research in girls studies, pointing out the dearth of material that explicitly addresses the lives and experiences of transgender girls and the urgent imperative of including them. It is therefore with great pleasure that we note the forthcoming special issue of Girlhood Studies: An Interdisciplinary Journal on Queering Girlhood to be guest edited by Barbara Jane Brickman to address directly these complex invisibilities in the field.

A further notable invisibility at IGSA 2016 was class, with just one paper, presented by Georgia Newton, that was explicitly concerned with issues of class, in this instance working-class girls' media consumption in the UK. Despite class being central to the work of the Centre for Contemporary Cultural Studies, mentioned above as one of the birthplaces of girls studies, class has become an almost near invisibility in contemporary girls studies despite the global trend toward economic hardship and the increased imposition of measures of austerity. At the 2016 "Association for Cultural Studies Crossroads" Conference one of the editors of this special issue, Vic- 
toria Cann, lamented the absence of questions of class in girls studies. In this paper Cann (2016), questioned why it was that despite what Yvette Taylor (2016) has claimed to be something of a "resurgence of interest in class across disciplines" (4), this does not seem to have been taken up by girls studies. Cann argued that it is the dominance of neoliberal subjectivities that render class subjectivities invisible. It follows, in terms of the postfeminist sensibilities mentioned above, that if these young, female, ideal neoliberal subjects are presumed to have the capability for survival in the new political and economic system (Walkerdine et al. 2001) it is perhaps inevitable that class has been erased without examination. Although there is some work that explores working class girls, this is dispersed across disciplines like, for example, the psychosocial (Reay 2005), educational (Archer at al. 2007; Evans 2009; Plummer, 2000; Ringrose 2013) and the socioeconomic (Walkerdine et al. 2001). Inclusive interdisciplinary spaces such as IGSA should be an ideal site for the interrogation of these questions.

In our final reflection on absences, we mention Anastasia Todd's paper, which has been adapted for this special issue, since it was the only one to engage with disabled girlhood(s). Todd's focus on deaf vlogger, Rikki Poynter, raises important questions about non-able-bodied girlhood. In the years since the conference, work in the area has begun to grow and the intersections of ability, age, and gender are starting to shape how we understand the unique forms of oppression these young people face, (and sometimes) resist, and overcome. Alongside Todd are emergent thinkers Sarah Hill and Amanda Ptolomey, both of whom are working in ways that will make disabled girls' voices and bodies more visible in girls studies.

\section{This Special Issue}

This collection presents some exciting developments in the field of girls studies, in particular, work examining girls as media producers and consumers. Each of the articles described in the next section was originally presented at the 2016 IGSA Conference and each uses media texts as a lens through which to examine broader social and political contexts that inform the construction of girlhood.

\section{Historical Girls}

Both Nickianne Moody and Joan Ormrod remind us of the importance of historicizing girlhood in their respective articles on British girls' periodicals 
from the twentieth century. Moody's insightful reflections on the construction of the Femorabilia collection, held at Liverpool John Moores University, explores what is at stake in capturing and recording girls' reading cultures. Indebted to McRobbie's canonical work on outlining the significance of girls' cultural consumption, Moody makes clear the intellectual and political potential of this collection. Working from McRobbie's premise that girls' and women's periodicals "are powerful ideological forces" (1990: 83) in need of critical interrogation, Moody outlines the ways in which the archive allows for the sustained analysis of those materials so often erased from history. Indeed, she writes, these periodicals already appear unfamiliar to many undergraduate students; the reading cultures and lived experiences associated with such texts are at risk of being forgotten entirely. That such cultural texts were so central to girls' lives (as well as the development of the field of girls studies) demonstrates the urgency for such archives to be established since the texts that they hold tell us so much about contemporaneous notions of gender, youth, race, citizenship, and morality.

Joan Ormrod's article is a testament to the importance of collections like Femorabilia, insofar as it demonstrates the value such materials have for our current understanding of girls' cultural consumption. Moreover, Ormrod's decision to focus on those lesser known (though significant) UK comic texts contributes to the same political goals as does the Femorabilia collection-the preservation and analyses of girls' media-as production began to recover after World War II and post-war girlhood in the British context was reconstructed. In her analysis of Mirabelle, Valentine, Roxy and Marilyn, Ormrod explores the materiality of comics (and, more specifically, the free gifts that readers often received) and the role they played in hailing girl teen audiences. As an aspect often sidelined in many analyses of popular print texts, materiality, as Alison Piepmeier (2009) has argued, is a significant feature of print texts insofar as it often produces embodied communities through the physical encounters with texts that can "reconnect us to our bodies and to other human beings" (58). Ormrod argues not only that the materiality of the free gifts served to create and sustain intimacy between the teen fan and pop stars of the era, but also that an analysis of these texts, and the cultural practices they encouraged, can help us understand subsequent girl fandoms and subcultures. In so doing, we become able to reconstruct the reading practices of girls and consider their subversive potential.

Carrie Rentschler and Samantha Thrift (2015) argue that "the ephemeral acts, artefacts and cultural infrastructures generated by feminist-identified movements and practitioners often get lost in the official and popular record, 
despite their political significance and potentially transformative power" (240). This is certainly the case for girls whose activism is often marginalized or not recognized as political. The texts held in the Femorabilia collection, and those analyzed by Ormrod, though perhaps not explicitly feminist, are certainly spaces in which girls' culture is made visible and valued. Moreover, both articles suggest that the intersection between text and reading practices is perhaps where more subversive and radical practices can take place, and that it is therefore necessary to preserve those historical materials so that we might gain access to these experiences.

\section{Girlhood Online}

While the materiality of those texts identified in Ormrod's and Moody's work is of importance, digital texts (in some cases more ephemeral) must also be preserved and curated. Thus, in addition to archiving historical girls' culture, capturing the complexities and nuances of contemporary digital and participatory cultures in which it is also possible to access the experiences of consumers, was also a crucial element that guided IGSA 2016. Looking specifically at YouTube as a central participatory platform in which cultural identities are (re)produced, Anastasia Todd and Catherine McDermott explore (in different contexts) the ways in which the site functions as a space in which girlhoods and youth femininities are questioned and contested. Todd provides a welcome correction to the above-mentioned absences in girls studies when it comes to the lives of disabled girls. In her article, she examines the production and consumption of disabled girlhoods, using the channel of Rikki Poynter, a deaf vlogger, as a case study. Todd analyzes the comments sections on Poynter's channel and reveals the intense affective responses of its users. On the one hand, these responses speak to the political work of Poynter in raising disability awareness, but, on the other, they serve to (re)construct or reconfigure Poynter's so-called disabledness through what Todd describes as a postfeminist and ablenationalist lens. In so doing, Poynter's performance of disabled girlhood is coded as exceptional and luminous and this, as Todd points out, ultimately functions to further exclude other bodies and ensure that a collective, radical, inclusive movement can never be realized.

McDermott also provides a counter narrative to those overtly celebratory accounts of digital media as a space for feminist activism as she seeks to capture the contradictory nature of online media content. Taking the videos of YouTube comedian, Grace Helbig, as a case study, McDermott applies a similar theoretical framework to that of Todd, to make sense of contemporary postfeminist media culture. Using affect theory, $\mathrm{McDermott}$ argues that 
Helbig's appeal to girl audiences lies in the ways in which she simultaneously problematizes postfeminist ways of living and the resulting expectations placed on girls to perform (impossible) idealized feminine identities, while also failing to offer alternative ways of being. Using the work of Lauren Berlant (2011) and her concept of cruel optimism, McDermott provides an insightful reading of the structures and practices of what she calls girling in the contemporary postfeminist moment.

Continuing to explore the complex and contradictory uses of digital spaces for women's and girls' empowerment and simultaneous oppression, Aria Halliday's work explores the racist appropriation and circulation of black women's bodies online. Tracking the lifecycle of Nicki Minaj's Anaconda cover image, Halliday explores the violent cooption of Minaj's body in memetic culture in the context of consumer capitalism. Applying her construction of what she calls Anaconda Feminism to the reading of Minaj's star image, Halliday considers the complicated ways in which black women celebrities negotiate public life. Perhaps the most pressing contribution Halliday's work makes to girls studies is her reminder that black girls' bodies are not awarded the same distinction in the category between womanhood and girlhood that can be said of girls of other racial backgrounds (especially white girls). Halliday draws our attention to the continued need for meaningful intersectional interrogation in our approach to girls studies. In concluding, she considers what is at stake in the digital mutilation of black female bodies in a space in which black women and girls have sought the representation, refuge, and community they are routinely refused in offline spaces.

\section{Other Women on Other Screens}

The symbolic work the bodies of women and girls are forced to undertake in contemporary media culture is addressed in Angharad Valdivia's article. In her discussion of the Half the Sky documentary film (2014), Valdivia examines the ways in which girls from the Global South are discursively constructed to function as both girls at risk and as can-do girls (Harris 2004), a continuing discourse in the field of girls studies. Valdivia's paper demonstrates how celebrity ambassadors are positioned as saviors and surrogate mother figures. These celebrity figures also represent the philanthropy of the Global North and are therefore depicted as aiding the successful transition of girls from the Global South from being at-risk to being can-do, albeit temporarily. The analysis of this particular documentary serves as a useful case study in furthering our understanding of mediated Western savior impulses in the context of neoliberal consumer capitalism. 
Alongside more traditionally academic papers, IGSA 2016 was proud to host a number of creative panels in which academics, activists, and practitioners could share their ground-breaking work in alternative formats. One such delegate was feminist academic and filmmaker, Eylem Atakav, who presented her film, Growing Up Married (2016), a documentary about four women in Turkey who were forced into marriage as young girls. To capture the spirit of these panels, we have included Zahra Khosroshahi's interview with Atakav about the process of making the film, its reception, and her experiences of teaching and researching sensitive subjects, in this case gender-based violence in the context of the Middle East. Khosroshahi's interview provides insight into many of the challenges facing feminist researchers who attempt to affect change that benefits the lives of girls around the globe while resisting the savior narrative highlighted by Valdivia.

Throughout the conference we argued for representations of girlhood to be taken seriously, working from the assumption that one has to see it to be it. With this in mind, we conclude this collection on girls as media producers and consumers with a series of book reviews of contemporary work that considers the opportunities (or lack thereof) for girls both now and in the past. Colette Slagle's review of Michele Paule's Girlhood, Schools, and Media: Popular Discourses of the Achieving Girl (2016) examines the construction of the achieving girl in popular media and its potential impact on girls' experience of the world. Katherine Darvesh provides a comprehensive account of Marelene Rayner-Canham and Geoff Rayner-Canham's book, $A$ Chemical Passion: The Forgotten Story of Chemistry at British Independent Girls' Schools, 1820s-1930s, (2017) that reconstructs the history of girls' education in relation to STEM subjects. Finally, Bernice Loh reviews Rebecca Raby and Shauna Pomerantz's empirical study of girls' experiences of being smart in the Canadian education system in Smart Girls: Success, School, and the Myth of Post-Feminism (2011).

\section{Emergent Themes}

In this special issue we have focused specifically on articles that engage with media as an overarching theme to point to the exciting state of the field. What is evident in all these articles is the gradual rendering visible of previous blind spots in girls studies. While these invisibilities are being addressed by scholars such as those published in this special issue, it is fair to say that we still know much more about heterosexual, able-bodied, Anglophone, 
white, cis-gender girls than we do about any other group of girls. This is, in part, we contend, a result of the structures of inequality that continue to shape the higher education field. As editors of this special issue we are complicit in the reproduction of these inequalities. While we have sought to bring together voices that represent the under-represented in girls studies, we, three white, cis-gender females, remain the gatekeepers to this special issue. We recognize that there is much work to be done if IGSA is to succeed in achieving the goal of creating a welcoming, diverse, and inclusive network of global scholars across disciplines. We await the second IGSA conference in 2019 with excitement and hope that it will move us all closer to this goal.

\section{Acknowledgments}

We are deeply indebted to the scholars of girlhood studies who came before us. In relation to the 2016 IGSA conference we would thank our sponsors, Berghahn Books; Feminist and Women's Studies Association; ResNet; and the University of East Anglia. The conference organizers were Victoria Cann, Sarah Godfrey, Su Holmes, Jessalynn Keller, Yvonne Tasker, and Helen Warner. The conference would not have been possible without the labor undertaken by Briony Hannell; Catrina Laskey; Charlene Katuwawala; Cherry Styles; Erica Horton; Helena Dare-Edwards; Katy Scales; Ksenia Boom; Marie-Alix Thouaille; Michele Meek; Molly Taylor; Oliver Brooks; Olivia Belton; and Rebecca Wildner.

We appreciate the support of John Charmley and Mark Jancovich as heads of department. We would also like to think the members of the International Girls Studies Association steering committee.

A special mention must go to Claudia Mitchell for her role in providing us with an opportunity to guest edit this issue.

For her support in the creation of this Special Issue we thank Ann Smith for her editorial work. We also extend our thanks to those who acted as peer reviewers for the articles that appear in this issue.

$\cos$

VICTORIa CANN is a Lecturer at the University of East Anglia. Her Girls Like This: Boys Like That (2018) explores the reproduction of gender during youth. Deeply committed to the integration of feminist theory and practice, she is one of the founders of Day of the Girl Norwich, a founding member of IGSA, and part of the \#ResSisters. Email: v.cann@uea.ac.uk 
SARAH GODFreY is a Senior Lecturer at the University of East Anglia where she teaches and researches feminist media studies. She has written about British Tween culture and representations of family and gender in Cbeebies (with Su Holmes). She is one of the founders of Day of the Girl Norwich. Email: s.godfrey@uea.ac.uk

Helen Warner is a Lecturer in Cultural Politics, Communications and Media Studies at the University of East Anglia. Her research interests include feminism, gender and production cultures. She is the author of Fashion on Television (2014) and co-editor, with Heather Savigny, of The Politics of Being a Woman (2014). Email: helen.warner@uea.ac.uk

\section{References}

Archer, Louise, Anna Halsall, and Sumi Hollingworth. 2007. "Class, Gender, (Hetero)Sexuality and Schooling: Paradoxes within Working-Class Girls' Engagement with Education and Post-16 Aspirations." British Journal of Sociology of Education 28 (2): 165-180.

Cann, Victoria. 2016. "Classing Girls: (Re)Considering the Role of Class in

British Girls' Lives." Paper presented at the Crossroads in Cultural Studies Conference, University of Sydney, Australia, 14-17 December.

de Jesús, Melinda. 2016. "Gender Fluidity in Girlhood." Paper presented at the International Girl Studies Association Conference, University of East Anglia, Norwich, UK, 7-9 April.

Driscoll, Catherine. 2002. Girls: Feminine Adolescence in Popular Culture and Cultural Theory. New York: Columbia University Press.

Driscoll, Catherine. 2016. "The Girl: Dynamics of Anxiety and Reassurance."

Paper presented at the International Girl Studies Association Conference, University of East Anglia, Norwich, UK, 7-9 April.

Emejulu, Akwugo. 2018. "On the Problems and Possibilities of Feminist Solidarity:

The Women's March One Year On.” Progressive Review 24 (4): 267-273.

Evans, Sarah. 2009. "In a Different Place: Working-Class Girls and Higher Education." Sociology 43 (2): 340-355.

Gill, Rosalind. 2007. Gender and the Media. Cambridge, UK: Polity Press.

Gill, Rosalind, and Christina Scharff, eds. 2011. New Femininities: Neoliberalism and Subjectivity. New York: Palgrave Macmillan.

Griffin, Christine. 1985. Typical Girls? Young Women from School to the Job Market. London: Routledge \& Kegan Paul.

Griffin, Christine. 2004. "Good Girls: Bad Girls: Anglocentricism and Diversity in the Constitution of Contemporary Girlhood." In All About the Girl:

Culture, Power and Identity, ed. Anita Harris, 29-42. New York: Routledge. 
Goodfellow, Maya. 2016. "A Toxic Concoction Means Women of Colour Are Hit Hardest by Austerity." The Guardian, 28 November.

https://www.theguardian.com/commentisfree/2016/nov/28/toxic-concoctionwomen-colour-pay-highest-price-austerity (accessed 17 September 2018).

Gonick, Marnina. 2006. "Sugar and Spice and Something More Than Nice?

Queer Girls and Transformations of Social Exclusion." In Girlhood: Redefining the Limits, ed. Yasmin Jiwani, Candis Steenbergen and Claudia Mitchell, 122137. Montreal, Canada: Black Rose Books.

Gonick, Marnina, Ileana Jimenez, Hanna Retallack, and Jessica Ringrose. 2016. "Pedagogies of Girlhood: Schools, Feminism and Media." Paper presented at the International Girl Studies Association Conference, University of East Anglia, Norwich, UK, 7-9 April.

Harris, Anita. 2004. Future Girl: Young Women in the Twenty-First Century. London, UK: Routledge.

Jimenez, Ileana. 2016. "Feminism-in-Schools Featured at First International Girls' Studies Association Conference." Feminist Teacher, 30 May. https:// feministteacher.com/2016/05/30/feminism-in-schools-featured-atinternational-girls-studies-association-conference/ (accessed 20 September 2018).

Kearney, Mary Celeste. 2006. Girls Make Media. London, UK: Routledge. Kearney, Mary Celeste. 2009. "Coalescing: The Development of Girls' Studies." NWSA Journal 21 (1): 1-28.

Kearney, Mary Celeste. 2016. "Girls Make Media: Then, Now, and So What?" Paper presented at the International Girl Studies Association Conference, University of East Anglia, Norwich UK, 7-9 April.

Keller, Jessalynn. 2016. Girls' Feminist Blogging in a Postfeminist Age. New York: Routledge.

Maart, Rozena. 2016. "The Slave Girls." Paper presented at the International Girl Studies Association Conference, University of East Anglia, Norwich, UK, 7-9 April.

McRobbie, Angela. 1978a. "Working Class Girls and the Culture of Femininity." In Women Take Issue: Aspects of Women's Subordination, ed, Women's Studies Group, Centre for Contemporary Cultural Studies, (96-108). London: Hutchinson University Library.

McRobbie, Angela. 1978b. Jackie: An Ideology of Adolescent Femininity.

Birmingham, UK: Centre for Contemporary Cultural Studies.

McRobbie, Angela. 1990. Feminism and Youth Culture: From Jackie to Just Seventeen. Basingstoke, UK. Macmillan.

McRobbie, Angela, and Mica Nava.1984. Gender and Generation. Basingstoke, UK. Macmillan.

Mitchell, Claudia, and Jacqueline Reid-Walsh. 2005. 7 Going on Seventeen: Tween Studies in the Culture of Girlhood. London, UK: Peter Lang. 
Monaghan, Whitney. 2016. Queer Girls, Temporality and Screen Media: Not 'Just a Phase.'London: Palgrave Macmillan.

Piepmeier, Alison. 2009. Making Media, Doing Feminism. New York: New York University Press.

Plummer, Gillian. 2000. Failing Working-Class Girls. Stoke-On-Trent, UK: Trentham.

Reay, Diane. 2005 “'Beyond Consciousness? The Psychic Landscape of Social Class.” Sociology 39 (5): 911-928.

Reinke, Rachel. 2016. "Towards a Theory of Transgender Girlhood ..." Paper presented at the International Girl Studies Association Conference, University of East Anglia, Norwich, UK, 7-9 April

Rentschler, Carrie A., and Samantha C. Thrift. 2015. "Doing Feminism: Event, Archive, Techné.” Feminist Theory 16 (3): 239-249.

Ringrose, Jessica. 2013. Postfeminist Education? Girls and the Sexual Politics of Schooling. Abindgon, UK: Routledge.

Russell, Lucy, Rachel Alsop, Lucy Bradshaw, Suzanne Clisby, and Kerry Smith. 2016. Plan UK Report: The State of Girl's Rights in the UK. London: Plan UK.

Taylor, Yvette. 2007. Working Class Lesbian Life: Classed Outsiders. New York: Palgrave.

Todd, Anastasia. 2016. "There are More Important Things That Need to be Talked About Than Taupe Eyeshadow: Virtual (Dis) Orientations and Luminosity of Disabled Girlhood" Paper presented at The International Girl Studies Association Conference, University of East Anglia, Norwich, UK. 7-9 April. Walkerdine, Valerie, Helen Lucey, and June Melody. 2001. Growing Up Girl: Psychosocial Explorations of Gender and Class. London: Palgrave Macmillan.

\section{Filmography}

Atakav, Eylem. 2016. Growing Up Married. UK.

\section{Notes}

1. Girls-Studies.org https://girlsstudies.org

2. Hey Girl Global is an "international network of teachers, students, and creatives studying the intersection of girl, urban, and media cultures, worldwide" (2018: n.p.) See Hey Girl Global Twitter https://twitter.com/heygirlglobal?lang=en 
